\title{
Uygulamalı Bilimler Yüksekokullarının Muhasebe Eğitimine Etkisi: Muhasebe Bölümleri Ders Programları Üzerine Bir İnceleme*
}

\author{
Mehtap KARAKOÇ
}

ÖZ

Son yıllarda yaşanan denetim skandalları muhasebe eğitiminin önemini ortaya koymuştur. Muhasebe dünyasında yalnızca kayıt tutan çalışanlardan çok, iyi eğitimli, sektörü bilen, etik değerlere bağlı, donanımlı işgücüne ihtiyaç bulunmaktadır. Türkiye'de lisans seviyesinde İktisadi ve İdari Bilimler fakülteleri ve İşletme fakültelerinde verilen muhasebe eğitimi uygulamadan uzak teorik şekilde yapılmaktadır. Yükseköğretimdeki yeni eğitim kurumlarından olan Uygulamalı Bilimler Yüksekokulları belirli alanlarda öğrenci yetiştiren, ağırlıklı yabancı dil eğitimi ve zorunlu yaz stajları ya da iş başında eğitim programı ile sektörle işbirliği halinde pratik eğitim almış öğrenciler yetiştirmektedir. Bu çalışmanın amacı; Uygulamalı Bilimler Yüksekokulları (UBYO) ve Uygulamalı Bilimler Fakültelerinde (UBF) Muhasebe bölümlerindeki ders programları incelenerek, muhasebe derslerinin ders kredisi ve ders sayısı açısından yeterliliğini ölçmek ve uluslararası muhsebe eğitimi standartları bağlamında muhasebe eğitimine katkısını ortaya koymaktır.

Anahtar Kelimeler: Muhasebe, Muhasebe Eğitimi, Uygulamalı Bilimler Yüksekokulu, Uluslararası Muhasebe Eğitimi Standartları

JEL Sinıflandırması: M41

\section{The Impact of Schools of Applied Sciences on Accounting Education: An Analysis on Curricula of Accounting Departments}

\begin{abstract}
In recent years audit scandals have revealed the importance of accounting education. In the world of accounting there is a need for a well-educated, sector aware, ethically-equipped, well-trained labour force rather than employees keeping records. Accounting education at bachelor's level is given at the faculty of economics and administrative sciences or faculty of business administration in universities in Turkey. The School of Applied Sciences, which are one of the new educational institutions in higher education, educates students who train students in certain fields and who have received practical training in cooperation with the sector through predominantly foreign language education and compulsory summer internships or on-the-job training program. The aim of this study is to examine the curriculum of Accounting Departments of the Schools of Applied Sciences (UBYO) and Faculties of Applied Sciences (UBF), to measure the adequacy of accounting courses in terms of course credits and number of courses and to reveal its contribution to accounting education in the context of international accounting education standards.
\end{abstract}

Keywords: Accounting, Accounting Education, Applied Sciences College, International Accounting Education Standards

JEL Classification: M41

Geliş Tarihi / Received: 13.09.2019 Kabul Tarihi / Accepted: 28.11.2019

\footnotetext{
* Bu çalışma 21-23 Eylül 2017 tarihlerinde Uşak’ta düzenlenen 1. Uluslararası Uygulamalı Sosyal Bilimler Kongresi'nde sunulan bildirinin yeniden düzenlenmiş ve geliştirilmiş halidir.

** Dr. Öğr. Üyesi, Uşak Üniversitesi, Uygulamalı Bilimler Yüksekokulu, Muhasebe Bilgi Sistemleri Bölümü, erdemmehtap@hotmail.com, ORCID: 0000-0003-0349-4571.
} 


\section{GİRIŞ}

Son yıllarda dünyada muhasebe ve denetim alanında yaşanan olumsuz gelişmeler, işletmelerin ürettikleri finansal bilgilerin ne derece önemli olduğunu ortaya koymuştur. Doğru ve güvenilir bilgiye olan ihtiyacın artmasıyla bu bilgiyi sağlayan muhasebe sisteminin de yetkinliği önem kazanmıştır. Muhasebe sistemi içinde doğru ve güvenilir finansal bilgiyi sağlayacak olan muhasebe çalışanlarının aldıkları muhasebe eğitiminin kalitesi, bu ihtiyacı karşılayabilir nitelikte olmalıdır. Muhasebe eğitiminin kalitesi ülkeden ülkeye farklılık göstermekle birlikte, kalitenin sağlanması konusunda üniversitelere büyük rol düşmektedir.

Muhasebe eğitiminin kalitesi konusunda dünyada çalışmalar yapan kurumların başında Uluslararas1 Muhasebeciler Federasyonu (International Federation of Accountants-IFAC) gelmektedir. Bu amaçla IFAC bünyesinde kurulan Uluslararası Muhasebe Eğitim Standartları Kuruluna (International Accounting Education Standard Board- IAESB) finansal, operasyonel ve idari destek sağlamaktadır. IAESB, IFAC üye kuruluşları ve profesyonel muhasebe eğitimiyle ilgili taraflar için eğitim standartlarını ve uygulama rehberlerini geliştiren bağımsız bir kurumdur (IAESB, 2017 Handbook). 2005 yılından itibaren muhasebe eğitimi standartları yayınlanmaya başlamıştır. Uluslararası Muhasebe Eğitim Standartları Kurulu (IAESB TM), teknik yeterlik ve mesleki beceriler, değerler, etik ve tutumları belirleyen mesleki muhasebe eğitimi alanında standartlar oluşturarak kamu yararına hizmet eden bağımsız bir standart belirleme organıdır. IAESB, faaliyetleri ile kamuoyunda güvenin güçlenmesine katkıda bulunarak muhasebe mesleğinin yeterliliğini arttıran Uluslararası Eğitim Standartlarını geliştirerek ve uygulamaya koyarak eğitimini geliştirir (https://www.iaesb.org/about-iaesb).

Bir profesyonel muhasebe eğitim programının içeriği, uygun mesleki yetkinliği geliştirme konusunda muhasebeci olmak isteyenleri desteklemektedir. Mesleki yeterlilik, (a) teknik yeterlilik, (b) mesleki beceriler ve (c) mesleki değerler, etik ve tutumların entegrasyonu ve uygulanmasıdır. Yeni IES'lerin her biri, muhasebe meslek mensuplarının arzulanması gereken mesleki yeterliliği tanımlayan yetkinlik alanlarını ve öğrenme çıktılarını belirtmektedir.

1 Temmuz 2015 tarihinden itibaren geçerli olan bu yeni standartlar, muhasebe meslek mensuplarına, eğitim organizasyonlarına, işverenlere, düzenleyicilere, hükümet yetkililerine ve muhasebe meslek mensuplarının öğrenimini ve gelişimini destekleyen diğer paydaşlara yardımcı olmayı amaçlamaktadır (www.ifac.org).

IES 1 Profesyonel Muhasebe Eğitim Programlarına Giriş Şartları

IES 2 İlk Mesleki Gelişim- Teknik Yeterlilik

IES 3 İlk Mesleki Gelişim- Mesleki Beceriler

IES 4 İlk Mesleki Gelişim- Mesleki Değerler, Etik ve Davranışlar

IES 5 İlk Mesleki Gelişim- Uygulama Deneyimi

IES 6 İlk Mesleki Gelişim- Mesleki Yeterliliklerin Değerlendirilmesi

IES 7 Sürekli Mesleki Gelişim

IES 8 Finansal Tablo Denetiminden Sorumlu Ortaklar için Mesleki Yeterlilik

IES 1'de meslek mensuplarının sadece iyi düzeyde matematik bilgisi ve okuryazarlığa sahip olmanın yeterli olmadığı, üniversite ve dengi okullardan mezun olmaları gerektiği belirtilmektedir (A9-para 8-10).

IES 2, IES 3, IES 4, IES 5 ve IES 6 meslek mensuplarının Temel Mesleki Gelişim sonunda gösterilmesi gereken teknik yeterlik için öğrenme çıktılarını öngörür. IES 2, IES 3 ve IES 4 standartları 2014 yılında güncellenerek isimleri değiştirilmiş, 1 Temmuz 2015 tarihinden itibaren de uygulanmaya başlanmıştır. 
IES 2; teknik yeterlilik, mesleki bilgiyi standartta tanımladığı şekilde yerine getirmek için uygulayabilme yeteneğidir. Dolayısıyla meslek mensuplarının bilgi düzeyinin arttırılmasıyla mesleğin kalitesinin yükseltilmesi amaçlanmaktadır. IES 2'de teknik yeterliliğin sağlanması için yeterlilik alanları ve bunların öğrenme çıtılarına yer verilmiştir. Bu alanlar; finansal muhasebe ve raporlama, yönetim muhasebesi, finans ve finansal yönetim, vergi, denetim ve güvence, denetim risk yönetimi ve iç kontrol, iş hukuku ve düzenlemeler, bilgi teknolojisi, işletme ve örgütsel çevre, ekonomi, işletme stratejileri ve yönetimdir (A8-A12).

IES 3'de yer alan mesleki beceriler, mesleki yeterliliği göstermek için meslek mensuplarının teknik yeterlilik, mesleki değerler, etik ve tutumlarla bütünleştiği kişiler arası iletişim, entellektüel, bireysel ve örgütsel becerilerdir.

IES 4'de meslek mensuplarının Temel Mesleki Gelişim sonuna kadar göstermesi gereken mesleki değerler, etik ve davranışlar için öğrenme çıktılarını öngörür. Mesleki değerler, etik ve tutumlar, muhasebe meslek mensuplarını bir meslek mensubu olarak tanımlayan davranış ve özellikler olarak tanımlanır. Bunlar, mesleki davranışın ayırt edici özelliklerini tanımlarken genellikle gerekli olan etik ilkeleri içermektedir.

IES 5, pratik tecrübenin meslek mensuplarının yetkinliğinin geliştirilmesiyle ilişkili olduğunu ifade etmektedir. IES 5'de uygulama deneyiminin mesleki bir eğitim programının tamamlanmasının ardından veya eğitim programıyla eş zamanlı yapılabileceğini belirtilmektedir (A8-para 12-13). Ayrıca standartta uygulama deneyimi için süre 3 yıl olarak belirtilmiştir. Ancak 3 yıllık süre muhasebe ve ilgili alanlarda 2 yıllık yüksek lisans derecesi kısaltılabilmektedir (A12-para 15).

IES 6 meslek mensuplarının mesleki yeterliliğini değerlendirmek için gerekli unsurları ele almaktadır. Standart bu değerlendirmenin mesleğin güvenilirliğini arttıracağını ve kamu menfaatinin korunacağını vurgulamaktadır. Değerlendirmelere yazılı sınavlar, sözlü sınavlar, nesnel testler, bilgisayar destekli testler, işyerinde işverenin yeterlilik değerlendirmesi, işyerindeki faaliyetlerinin portfolyolarının incelenmesi örnek olarak olarak verilebilir.

IES 7'nin kapsamı müşterilere, işverenlere ve diğer paydaşlara yüksek kaliteli hizmetler sunmak ve böylece mesleğe duyulan güveni güçlendirmek için gerekli mesleki yeterliliği geliştirmek ve sürdürmeyi içermektedir. Bu standarda göre; her bir meslek mensubunun her üç yıllık dönemde 120 saatlik mesleki gelişim faaliyetinin tamamlanması gerekmektedir.

IES 8 finansal tablo denetiminden sorumlu ortaklar için mesleki yeterliliği kapsamaktadır. Mali tabloların denetimlerinden sorumlu bir Nihai Ortak'ın rolünü yerine getirirken muhasebe meslek mensuplarının geliştirmesi ve sürdürmesi gereken mesleki yeterliliği belirtmektedir.

Standartların Türkiye'de geçerliliğinin incelendiği Gökten ve Gökten (2016) çalışmalarında standartların beş tanesinin tamamen geçerli olduğu, IES 2 Temel Mesleki Gelişim- Teknik Yeterlilik ve IES 6 Temel Mesleki Gelişim- Mesleki Yeterliliklerin Değerlendirilmesi standartlarının kısmen geçerli olduğu ancak IES 3 Temel Mesleki GelişimMesleki Beceriler standardının ise Türkiye' de geçerli olmadığı sonucuna ulaşmışlardır.

Eğitim kalitesine eden ve rakamsal olarak ifade edilen faktörlerden birisi eğitim programlarındaki ders dağılımıdır. Bu dağılım, ders kredisi, ders saati ve ders sayısı ile belirlenebilmektedir. Bu çalışmanın amacı; Uygulamalı Bilimler Yüksekokulları (UBYO) ve Uygulamalı Bilimler Fakültelerinde (UBF) Muhasebe bölümlerindeki ders programları irdelenerek, muhasebe derslerinin ders kredisi ve ders sayısı açısından yeterliliğini ölçmek ve uluslararası muhasebe eğitimi standartları muhasebe eğitimine katkısını incelemektir. Çalışmanın bütünlüğü açısından çalışmanın bundan sonraki bölümlerinde UBYO, UBF ve diğer yüksekokullarının tamamından UBYO olarak bahsedilecektir. 


\section{LITERATÜR TARAMASI}

Türkiye'de önlisans ve lisans düzeyinde muhasebe eğitimi veren gerek devlet gerek vakıf üniversiteleri ile ilgili çalışmalar ve bunların muhasebe eğitimine katkılarının incelendiği çalışmalar literatürde yerini almıştır. Ancak lisans seviyesinde muhasebe ağırlıklı eğitim veren yükseköğretimdeki yeni kurumlardan olan Uygulamalı Bilimler Yüksekokullarını bu açıdan inceleyen bir çalışmaya tarafımızca rastlanmamıştır. Türkçe literatürde lisans seviyesinde verilen muhasebe eğitimi ve ilgili müfredatların incelendiği son on yılda ulaşılabilen çalışmalardan bazıları aşağıda yer almaktadır.

Zaif ve Ayanoğlu (2007) çalışmalarında Türkiye'deki üniversitelerin İşletme bölümlerinnin ders programlarını ortalama ders sayısı ve kredisi bakımından incelemiş, çalışmanın sonucunda işletme bölümlerinde yer alan derslerin \%14'lük kısmının muhasebe derslerine ait olduğunu saptamışlardır.

Uyar (2008) çalışmasında Akdeniz Üniversitesi'nde verilen muhasebe eğitimi uluslararası eğitim standartları kapsamında incelenmiştir. Buna göre; standartlara uygun eğitim veren bölümlerin işletme, iktisat ve maliye bölümleri olduğu belirlenmiştir. Ünal ve Doğanay (2009) çalışmalarında Sayıştay'da görevli ve lisans eğitiminde muhasebe dersleri almış 83 denetçiye yöneltilen anket sonucunda, muhasebe derslerinin müfredatta yeterli olmasına karşın kurumların ihtiyaçlarına cevap veremediği ortaya çıkmıştır.

Şengel (2010) çalışmasında sürekli muhasebe meslek eğitimi üzerinde durmuştur. Buna göre; üniversiteler, TESMER ve meslek odaları tarafından düzenlenen eğitimlerin mesleğin gelişim göstermesi bakımından önemi vurgulanmıştır. Terzi, Şen ve Solak (2013) çalışmalarında Bologna sürecinde Türkiye'de eğitim veren işletme bölümlerinde verilen muhasebe dersleri incelenmiştir. Çalışmanın sonucunda zorunlu muhasebe dersi bakımından ortalama altında kalan devlet üniversitesi oranı \%36 iken, bu oran vakıf üniversitelerinde $\% 42$ 'dir.

Erol ve Atmaca (2015) çalı̧̧malarında lisans seviyesinde muhasebe eğitimi veren fakültelerden mezun olan ve bu fakültelere yeni kayıt yaptıran öğrenci sayıları incelenmiştir. Buna göre son on yıl içinde mezun olan öğrenci sayısında \%59'luk bir artış meydana geldiği ortaya çıkmıştır.

Tazegül ve Karabayır (2015) çalışma konuları Kafkas ve Ardahan Üniversitesilerinde muhasebe dersi almış lisans öğrencileridir. Buna göre; araştırmaya konu olan öğrencilerin lisans eğitimi boyunca yeterli bilgi düzeyine ulaştığı belirlenmiştir. Demirci, Kıymaz ve Ağsakal (2015), 105 işletme bölümü üzerinde yaptıkları çalışmada ders sayısı ve ağırlıklı kredi bakımından müfredata uygun olan bazı üniversitelerin, çalışmada hesaplanan serbest muhasebeci ve mali müşavirlik staja başlama sınavı ağırlıklı puanlarının düşük olduğunu saptamışlardır.

Can ve Demirci (2016) çalışmalarında uluslararası eğitim standardı kapsamında Sakarya Üniversitesi'nde serbest muhasebeci mali müşavirlik belgesi alma hakkı tanınan 13 bölümün ders programları incelenmiştir. Bu çalışmanın sonucunda standarda en uygun bölümün işletme bölümü olduğu belirlenmiştir. Gökten ve Gökten (2016) çalışmalarında Uluslararası Muhasebe Eğitimi Standartları Kurumu tarafından yayınlanan sekiz standart incelenmiştir. Çalışmanın sonucunda Türkiye'de standartların beş tanesinin geçerli olmasına rağmen, iki standardın kısmen geçerli, diğerinin ise geçersiz olduğu sonucuna ulaşmışlardır.

Öztürk ve Erdoğan (2017) çalışmalarında Antalya, Burdur ve Isparta illerinde eğitim veren işletme bölümlerinde verilen muhasebe derslerinin analizi yapılmıştır. Buna göre; araştırma kapsamındaki üniversitelerde verilen muhasebe derslerinin sayısının fazla ancak seçmeli derslerin sayılarının artırılması gerektiğini, ayrıca muhasebe ders sayılarının ve niteliklerinin arttırılması gerektiği vurgulamıştır. 


\section{ARAŞTIRMANIN AMACI, KAPSAMI VE YÖNTEMI}

Bu çalışmada, lisans düzeyinde eğitim veren Uygulamalı Bilimler Yüksekokulu (UBYO), Uygulamalı Bilimler Fakültesi (UBF) ve diğer uygulamalı eğitim veren yüksekokullarının muhasebe bölümlerinde verilen eğitimin Uluslararası Muhasebe Eğitim Standartlarını ne ölçüde karşıladığı belirlenmeye çalışılmıştır.

Türkiye'de UBYO'ları, spesifik alanlarda uygulamaya yönelik verilecek eğitimle sektörün ihtiyaç duyduğu kalifiye işgücünü yetiştirmek amacıyla kurulmuştur. $\mathrm{Bu}$ nedenle muhasebe alanında lisans düzeyinde eğitim veren UBYO bünyesinde eğitim veren muhasebe bölümleri araştırmamızın kapsamındadır. Araştırmamıza konu olan Türkiye'de eğitim veren Uygulamalı Bilimler Yüksekokulları ve bağlı bulundukları üniversiteler Tablo 1'de yer almaktadır.

Tablo 1: Türkiye'de Uygulamalı Bilimler Yüksekokulu Muhasebe Bölümleri

\begin{tabular}{llll}
\hline \multicolumn{1}{c}{ Üniversite } & \multicolumn{1}{c}{ UBYO } & \multicolumn{1}{c}{ Bölüm } \\
\hline Afyon Kocatepe Üniversitesi (D) & Bolvadin UBYO & Muhasebe \\
\hline $\begin{array}{l}\text { Burdur } \begin{array}{l}\text { Mehmet } \\
\text { Üniversitesi (D) }\end{array} \\
\text { Bilecik Şeyh Edebali Üniversitesi (D) }\end{array}$ & EBYO & $\begin{array}{l}\text { Bucak Zeliha Tolunay Uygulamalı } \\
\text { Teknoloji ve İsletmecilik Yüksekokulu }\end{array}$ & Muhasebe ve Finans Yönetimi \\
\hline Dumlupınar Üniversitesi (D) & UBYO & Muhasebe ve Denetim \\
\hline $\begin{array}{l}\text { Isparta Uygulamalı } \\
\text { Üniversitesi (D) }\end{array}$ & Bilimler & Yalvaç Büyükkutlu UBYO & Muhasebe \\
\hline Kayseri Üniversitesi (D) & $\begin{array}{l}\text { İzzet Bayraktar Uygulamalı Bilimler } \\
\text { Necmettin Erbakan Üniversitesi (D) }\end{array}$ & Uygulamalı Bilimler Fakültesi & Muhasebe ve Finans Yönetimi \\
\hline Uşak Üniversitesi (D) & UBYO & Muhasebe ve Finans Yönetimi \\
\hline Trakya Üniversitesi (D) & Uzunköprü UBYO & Muhasebe Bilgi Sistemleri \\
\hline & & Muhasebe \\
\hline İstanbul Arel Üniversitesi (V) & UBYO & Muhasebe ve Finans Yönetimi \\
\hline Girne Amerikan Üniversitesi (V) & Uygulamalı Sosyal Bilimler & Muhasebe \\
\hline & Yüksekokulu & \\
\hline
\end{tabular}

Necmettin Erbakan Üniversitesi Uygulamalı Bilimler Fakültesi Muhasebe ve Finansal Yönetim bölümüne ait ders içerikleri eksik olduğu ve Girne Amerikan Üniversitesi Uygulamalı Sosyal Bilimler Yüksekokulu Muhasebe bölümü ders içeriklerine ulaşılamadığı için çalışmanın kapsamında yer almamaktadır. Böylece çalışmamız kapsamında 8 devlet, 1 de vakıf üniversitesi incelenmiştir.

Araştırmamıza dahil olan üniversitelerin ders müfredatları ve ders içerikleri incelenerek hazırlanan ders kredisi ve Avrupa Kredi Transfer Sistemi (AKTS) sayıları ile ilgili veriler Tablo 2 'de yer almaktadır. Buna göre zorunlu derslerin kredi ortalaması 127 iken, seçmeli derslerin kredi ortalaması 91 olmuştur. 
Tablo 2: Müfredatta Yer Alan Derslerin Dağılımı

\begin{tabular}{|c|c|c|c|c|}
\hline \multirow[t]{2}{*}{ Üniversite } & \multicolumn{2}{|c|}{ Zorunlu Dersler } & \multicolumn{2}{|c|}{ Seçmeli Dersler } \\
\hline & Kredi & AKTS & Kredi & AKTS \\
\hline Afyon Kocatepe Üniv. BUBYO & 110 & 176 & 138 & 203 \\
\hline Burdur MAE Üniv. ZTUTIYY & 141 & 225 & 18 & 19 \\
\hline Bilecik ŞEÜ Üniv. UBYO & 152 & 189 & 91 & 126 \\
\hline Dumlupınar Üniv. UBYO & 103 & 178 & 224 & 315 \\
\hline Isparta UBÜ YBUBYO & 122 & 177 & 82 & 152 \\
\hline Kayseri Üniv. İBUBF & 114 & 170 & 42 & 70 \\
\hline Uşak Üniv. UBYO & 148 & 180 & 102 & 126 \\
\hline Trakya Üniv. UUBYO & 114 & 168 & 93 & 155 \\
\hline İstanbul Arel Üniv. UBYO & 141 & 227 & 27 & 44 \\
\hline ORTALAMA & 127 & 188 & 91 & 134 \\
\hline
\end{tabular}

Seçmeli ders kredileri, müfredatta öğrenciye sunulan tüm seçmeli derslerin kredilerini kapsamaktadır. Örneğin öğrencinin bir dönemde 6 kredilik seçmeli ders seçmesi gerekirken, öğrenciye 12 kredilik seçmeli ders sunulmuşsa, 12 kredi dikkate alınmıştır.

Araştırmamıza göre muhasebe bölümlerinde öğrenim gören öğrencilerin, mezun olmak için almaları gereken krediler Tablo 3'te yer almaktadır. Buna göre UBYO'dan mezun olacak bir öğrencinin 4 yıllık muhasebe eğitimi boyunca ortalama 161 kredilik ders alması gerekmektedir. Zaif ve Ayanoğlu (2007) çalışmalarında Türkiye'de işletme bölümlerinden mezun olan öğrencilerin ortalama 158 kredilik ders aldığını tespit etmişlerdir. Bu açıdan UBYO muhasebe bölümlerinin mezuniyet kredi ortalamalarının işletme bölümlerine yakın olduğu söylenebilmektedir. Ayrıca Bologna süreci ile Türkiye'de bir öğrencinin lisans düzeyinde mezun olabilmesi toplam 240 AKTS'lik ders alması gerekmektedir. Ancak Türkiye'de aynı isimli derslerin bile üniversiteler arasında ders kredileri bakımından farklılıklarının olması sebebiyle, standart bir ders saati ve ders kredisi olmadığı için (Zaif ve Ayanoğlu, 2007: 127) mezuniyet kredileri her bölüm için değişmektedir.

Tablo 3: Mezuniyet Kredilerine göre Muhasebe Bölümleri

\begin{tabular}{lcc}
\hline \multicolumn{1}{c}{ Üniversite } & UBYO & Mezuniyet Kredisi \\
\hline Afyon Kocatepe Üniversitesi & Bolvadin UBYO & 151 \\
\hline Bilecik Şeyh Edebali Üniversitesi & UBYO & 194 \\
\hline Burdur MAE Üniversitesi & ZTUTiY & 156 \\
\hline Dumlupınar Üniversitesi & UBYO & 151 \\
\hline Isparta Uygulamalı Bilimler Üniversitesi & Yalvaç Büyükkutlu UBYO & 144 \\
\hline Kayseri Üniversitesi & İzzet Bayraktar UBYO & 156 \\
\hline Uşak Üniversitesi & UBYO & 190 \\
\hline Trakya Üniversitesi & Uzunköprü UBYO & 162 \\
\hline İstanbul Arel Üniversitesi (V) & UBYO & 149 \\
\hline & Ortalama & $\mathbf{1 6 1}$ \\
\hline
\end{tabular}


Mezuniyet kredileri bakımından zorunlu ve seçmeli derslerin dağılımı Tablo 4'te yer almaktadır. Bu tablo hazırlanırken üniversitelerin müfredatlarında bulunan ortak seçmeli ders havuzlarındaki dersler, seçmeli dersler kapsamında değerlendirilmemiştir. Buna göre; seçmeli derslerin toplam krediler içindeki payı incelendiğinde en yüksek oranın \%33 ile Afyon Kocatepe Üniversitesi'ne, en düşük oranın ise \%5 ile araştırmamızdaki tek vakıf üniversitesi olan İstanbul Arel Üniversitesi'ne ait olduğu görülmektedir. Bologna süreci ile seçmeli derslerin toplam dersler arasındaki oranının AKTS bakımından \%25 olması gerekmektedir. Ders kredileri bakımından değerlendirildiğinde sadece 5 bölümün bu oranların altında kaldığı görülmektedir. Zaif ve Ayanoğlu (2007) çalışmalarında seçmeli ders sayılarının yeterli olmadığını saptamışlar, Terzi, Şen ve Solak (2013) ise çalışmalarında seçmeli ders sayılarının yeterli düzeyde olmamasına rağmen Zaif ve Ayanoğlu çalışmasına göre artış yaşandığını vurgulamışlardır. Bu anlamda UBYO'lardaki muhasebe bölümleri seçmeli derslerin kredileri oranları bakımından yeterli seviyelerdedir. Seçmeli derslerin artışının eğitim kalitesinin artışına olumlu yansıyacağı düşünülmektedir (Terzi vd., 2013: 94).

Tablo 4: Mezuniyet Kredileri Bakımından Zorunlu/Seçmeli Ders Dağılımı

\begin{tabular}{lccccc}
\hline \multirow{2}{*}{ Üniversite } & \multirow{2}{*}{$\begin{array}{c}\text { Toplam } \\
\text { Kredi }\end{array}$} & \multicolumn{2}{c}{ Zorunlu Kredi } & \multicolumn{2}{c}{ Seçmeli Kredi } \\
\cline { 3 - 6 } & & Toplam & Yüzde & Toplam & Yüzde \\
\hline Afyon Kocatepe Üniversitesi & 151 & 101 & $\% 67$ & 50 & $\% 33$ \\
\hline Bilecik Şeyh Edebali Üniversitesi & 194 & 151 & $\% 78$ & 43 & $\% 22$ \\
\hline Burdur MAE Üniversitesi & 156 & 138 & $\% 88$ & 18 & $\% 12$ \\
\hline Dumlupınar Üniversitesi & 151 & 103 & $\% 68$ & 48 & $\% 32$ \\
\hline Isparta Uygulamalı Bilimler Üniversitesi & 144 & 109 & $\% 76$ & 35 & $\% 24$ \\
\hline Kayseri Üniversitesi & 156 & 114 & $\% 73$ & 42 & $\% 27$ \\
\hline Uşak Üniversitesi & 190 & 148 & $\% 88$ & 42 & $\% 22$ \\
\hline Trakya Üniversitesi & 162 & 114 & $\% 70$ & 48 & $\% 30$ \\
\hline İstanbul Arel Üniversitesi (V) & 149 & 141 & $\% 95$ & 8 & $\% 5$ \\
\hline
\end{tabular}

Araştırmamıza konu olan okulların müfredatları incelendiğinde ders sayıları, ders kredileri ve AKTS'leri bakımından derslerin ait olduğu alanlar Tablo 5'te yer almaktadır. IES 2'ye göre meslek mensuplarının finansal muhasebe ve raporlama, yönetim muhasebesi, finans ve finansal yönetim, vergi, denetim, bilgi teknolojisi, işletme, ekonomi gibi alanlarda almaları gereken yeterliliklerin UBYO'lar tarafindan karşılandığı görülmektedir. Ders sayıları bakımından araştırmamıza konu olan üniversitelerin zorunlu derslerde \%32, seçmeli derslerde $\% 27$ oranında öğrencilerine muhasebe ve deneim dersi verdikleri görülmektedir. Bu durum ders kredileri bakımından zorunlu derslerde \%36, seçmeli derslerde ise \%28'e çıkmaktadır. Ayrıca ders sayıları bakımından bu okullarda öğrenim gören öğrenciler, yök dersleri içinde iki adet yabancı dil dersi hariç, yabancı dil eğitimini $\% 5$ oranında zorunlu olarak almaktadır. 
Optimum Journal of Economics and Management Sciences, Vo1. 7, No. 1- http://dergipark.gov.trloptimum Karakoç - The Impact of Schools of Applied Sciences on Accounting Education: An Analysis on Curricula of Accounting Departments

Tablo 5: Muhasebe Bölümlerindeki Derslerin Ders Sayıları ve Ders Kredileri

\begin{tabular}{|c|c|c|c|c|c|c|}
\hline \multirow[t]{2}{*}{ Dersler } & \multicolumn{2}{|c|}{ Ders Sayısı } & \multicolumn{2}{|c|}{ Kredi } & \multicolumn{2}{|c|}{ AKTS } \\
\hline & Zorunlu & Seçmeli & Zorunlu & Seçmeli & Zorunlu & Seçmeli \\
\hline Muhasebe ve Denetim & 131 & 60 & 409 & 180 & 617 & 278 \\
\hline & $\% 32$ & $\% 27$ & $\% 36$ & $\% 28$ & & \\
\hline Ekonomi ve Finans & 48 & 46 & 142 & 135 & 208 & 202 \\
\hline İşletme/Yön.ve Org. & 23 & 39 & 67 & 106 & 95 & 161 \\
\hline Üretim ve Pazarlama & 3 & 16 & 8 & 46 & 12 & 74 \\
\hline $\begin{array}{l}\text { Matematik/Sayısal } \\
\text { Yön./Ekonometri }\end{array}$ & 36 & 1 & 102 & 3 & 142 & 4 \\
\hline Hukuk & 43 & 13 & 115 & 36 & 167 & 60 \\
\hline Etik/İşletme Etiği/Meslek Etiği & 3 & 6 & 7 & 17 & 10 & 25 \\
\hline Vergi & 11 & 4 & 32 & 11 & 50 & 19 \\
\hline Bilgi Teknolojileri & 13 & 3 & 38 & 10 & 45 & 14 \\
\hline Proje/Araştırma Dersleri & 6 & 6 & 16 & 16 & 27 & 25 \\
\hline YÖK Dersleri & 54 & - & 102 & - & 126 & - \\
\hline Yabancı Dil * & 22 & 11 & 65 & 30 & 70 & 46 \\
\hline Diğer & 6 & 21 & 15 & 52 & 22 & 75 \\
\hline Staj/İşbaşı Eğitim & 11 & - & 30 & - & 115 & - \\
\hline Toplam & 410 & 226 & 1148 & 642 & 1706 & 983 \\
\hline
\end{tabular}

Zaif ve Ayanoğlu (2007) Türkiye'deki işletme bölümleri üzerine yaptıkları çalışmada okutulan derslerin sadece \%14'lük payının muhasebe derslerine ait olduğunu belirtirken, Terzi, Şen ve Solak (2013) ise işletme bölümünde okutulan derslerin ortalama kredilerine bakıldığında devlet üniversitelerindeki muhasebe ve denetim derslerinin \%14'ü zorunlu ders iken, \%13'lük kısmının seçmeli ders olduğunu, vakıf üniversitelerinde ise bu durumun \%10'u zorunlu ders iken, \%11'inin ise seçmeli ders olarak okutulduğunu ifade etmişlerdir. Buna göre araştırmamıza konu olan bölümlerde ortaya çıkan tablo, bu bölümlerin muhasebe eğitimine katkıları açısından umut vericidir.

Tablo 6 incelendiğinde araştırmamıza konu olan bölümlerde verilen muhasebe ders sayıları, kredileri ve AKTS'leri bakımından en yüksek sayıya toplam 31 ders ile Dumlupınar Üniversitesi'nin ulaştığı görülmektedir. 
Tablo 6: Muhasebe Ders Sayıları Bakımından UBYO'lar

\begin{tabular}{lcccccc}
\hline \multirow{2}{*}{\multicolumn{1}{c}{ Üniversite }} & \multicolumn{2}{c}{ Ders Sayısı } & \multicolumn{2}{c}{ Kredi } & \multicolumn{2}{c}{ AKTS } \\
\cline { 2 - 7 } & $\mathrm{Z}$ & $\mathrm{S}$ & $\mathrm{Z}$ & $\mathrm{S}$ & $\mathrm{Z}$ & $\mathrm{S}$ \\
\hline Afyon Kocatepe Üniversitesi & 12 & 4 & 36 & 12 & 59 & 20 \\
\hline Bilecik Şeyh Edebali Üniversitesi & 16 & 10 & 62 & 30 & 79 & 41 \\
\hline Burdur MAE Üniversitesi & 16 & 1 & 48 & 3 & 68 & 3 \\
\hline Dumlupınar Üniversitesi & 15 & 16 & 46 & 50 & 73 & 75 \\
\hline Isparta Uygulamalı Bilimler Üniversitesi & 15 & 4 & 43 & 10 & 61 & 16 \\
\hline Kayseri Üniversitesi & 13 & 2 & 39 & 6 & 65 & 10 \\
\hline Uşak Üniversitesi & 17 & 8 & 53 & 24 & 68 & 38 \\
\hline Trakya Üniversitesi & 14 & 10 & 43 & 30 & 72 & 50 \\
\hline İstanbul Arel Üniversitesi $(\mathbf{V})$ & 13 & 5 & 39 & 15 & 72 & 25 \\
\hline
\end{tabular}

IES 2 meslek mensuplarının yeterlilik alanlarını ve bu alanlardaki ögrenme çıktılarını açılamaktadır (Parag A8-A12) Bu alanlar ve araştırmamıza konu olan üniversitelerin bu alanlarda müfredatlarında bulunan dersler Tablo 7'de yer almaktadır. Buna göre lisans düzeyinde muhasebe eğitimi veren üniversitelerin IES 2'ye uygun ders müfredatlarına sahip oldukları söylenebilecektir. Bunun yanında Yönetim, Risk Yönetimi ve İç Kontrol alanında dört üniversitenin ders müfredatlarına dersler eklemeleri tavsiye edilebilir.

Tablo 7: IES 2 Yeterlilik Alanlarına Göre Üniversitelerdeki Zorunlu/Seçmeli Dersler

\begin{tabular}{|c|c|c|c|c|c|c|c|c|c|}
\hline Yeterlilik Alanları & $\begin{array}{l}\text { Afyon } \\
\text { Üniv. }\end{array}$ & $\begin{array}{l}\text { Bilecik } \\
\text { Üniv. }\end{array}$ & $\begin{array}{l}\text { Burdur } \\
\text { MAE } \\
\text { Üniv. }\end{array}$ & $\begin{array}{l}\text { DPU } \\
\text { Üniv. }\end{array}$ & $\begin{array}{l}\text { Isparta } \\
\text { Üniv. }\end{array}$ & $\begin{array}{l}\text { Kayseri } \\
\text { Üniv. }\end{array}$ & $\begin{array}{l}\text { Uşak } \\
\text { Üniv. }\end{array}$ & $\begin{array}{l}\text { Trakya } \\
\text { Üniv. }\end{array}$ & $\begin{array}{l}\text { Arel } \\
\text { Üniv. }\end{array}$ \\
\hline $\begin{array}{l}\text { Finansal Muhasebe } \\
\text { ve Raporlama }\end{array}$ & $\mathrm{Z}$ & $\mathrm{Z}$ & $\mathrm{Z}$ & $\mathrm{Z}$ & $\mathrm{Z}$ & $\mathrm{Z}$ & $\mathrm{Z}$ & $\mathrm{Z}$ & $\mathrm{Z}$ \\
\hline Yönetim Muhasebesi & $\mathrm{Z}$ & $\mathrm{Z}$ & $\mathrm{Z}$ & $\mathrm{Z}$ & $\mathrm{Z}$ & $\mathrm{Z}$ & $\mathrm{Z}$ & $\mathrm{Z}$ & $\mathrm{Z}$ \\
\hline $\begin{array}{l}\text { Finans ve Finansal } \\
\text { Yönetim }\end{array}$ & $\mathrm{Z}$ & $\mathrm{Z}$ & $\mathrm{Z}$ & $\mathrm{Z}$ & $\mathrm{Z}$ & $\mathrm{Z}$ & $\mathrm{Z}$ & $\mathrm{Z}$ & $\mathrm{Z}$ \\
\hline Vergi & $\mathrm{Z}$ & $\mathrm{Z}$ & $\mathrm{Z}$ & $S$ & $\mathrm{~S}$ & $S$ & $\mathrm{Z}$ & $\mathrm{S}$ & $\mathrm{Z}$ \\
\hline Denetim ve Güvence & $\mathrm{Z}$ & $\mathrm{S}$ & $\mathrm{Z}$ & $\mathrm{Z}$ & $\mathrm{Z}$ & $S$ & $\mathrm{Z}$ & $\mathrm{Z}$ & $\mathrm{Z}$ \\
\hline $\begin{array}{l}\text { Yönetim, Risk } \\
\text { Yönetimi ve İç } \\
\text { Kontrol }\end{array}$ & $S$ & $S$ & - & $S$ & - & - & $S$ & $S$ & - \\
\hline $\begin{array}{l}\text { İş Hukuku ve } \\
\text { Uygulamaları }\end{array}$ & - & $\mathrm{Z}$ & $\mathrm{Z}$ & S & S & - & $\mathrm{S}$ & $S$ & $\mathrm{Z}$ \\
\hline Bilişim Teknolojileri & $\mathrm{Z}$ & $\mathrm{Z}$ & $\mathrm{Z}$ & $\mathrm{Z}$ & $\mathrm{Z}$ & $S$ & $\mathrm{Z}$ & $\mathrm{Z}$ & $\mathrm{Z}$ \\
\hline İşletme ve Yönetim & $\mathrm{Z}$ & $\mathrm{Z}$ & $\mathrm{Z}$ & $\mathrm{Z}$ & $\mathrm{Z}$ & $\mathrm{Z}$ & $\mathrm{Z}$ & $\mathrm{Z}$ & $\mathrm{Z}$ \\
\hline Ekonomi & $\mathrm{Z}$ & $\mathrm{Z}$ & $\mathrm{Z}$ & $\mathrm{Z}$ & $\mathrm{Z}$ & $\mathrm{Z}$ & $\mathrm{Z}$ & $\mathrm{Z}$ & $\mathrm{Z}$ \\
\hline $\begin{array}{l}\text { Işletme Strateji ve } \\
\text { Yönetimi }\end{array}$ & - & $\mathrm{Z}$ & $\mathrm{Z}$ & $S$ & $\mathrm{Z}$ & $\mathrm{Z}$ & $S$ & $\mathrm{Z}$ & $\mathrm{Z}$ \\
\hline
\end{tabular}


Muhasebe standartları derslerinin müfredattaki durumları ile ilgili bilgilere Tablo 7'de yer verilmiştir. $\mathrm{Bu}$ dersin sadece bir üniversitede seçmeli ders olarak verildiği, bazı üniversitelerin müfredatlarında bu derse iki dönem yer verdiği, ancak ismi konusunda üniversiteler arasında bir mutabakatın var olmadığ görülmektedir. Terzi, Şen ve Solak (2013) Türkiye' de Türkçe eğitim veren işletme bölümleri üzerine yaptı̆̆ 1 çalışmada Türkiye Muhasebe ve Finansal Raporlama Standartları derslerinin "seçmeli ders" olduğu ve \%1 oranında olduğu sonucuna ulaşılmıştır. Bu açıdan bakıldığında UBYO'larda bu derse gerekli önemin verildiği görülmektedir.

Tablo 8: Muhasebe Standartları Derslerinin Durumu

\begin{tabular}{llcccc}
\hline \multicolumn{1}{c}{ Üniversite } & \multicolumn{1}{c}{ İsim } & Z/S & YY & Kredi & AKTS \\
\hline Afyon Kocatepe Üniversitesi & Uluslararası Muh. Fin. Raporlama Stan. & Z & 6 & 3 & 3 \\
\hline Bilecik Şeyh Edebali Üniversitesi & Uluslararası Muhasebe Standartları & Z & 6 & 3 & 4 \\
\hline Burdur MAE Üniversitesi & Muhasebe Standartları & $\mathrm{S}$ & 7 & 3 & 4 \\
\hline Dumlupınar Üniversitesi & Muhasebe Standartları & $\mathrm{Z}$ & 7 & 3 & 5 \\
\hline Isparta Uygulamalı Bil. Üniversitesi & Muhasebe Standartları & $\mathrm{Z}$ & 4 & 3 & 4 \\
\hline Kayseri Üniversitesi & Muhasebe Standartları & $\mathrm{Z}$ & 7 & 3 & 5 \\
\hline Uşak Üniversitesi & Muhasebe Standartları I & $\mathrm{Z}$ & 7 & 4 & 4 \\
\cline { 2 - 6 } & Muhasebe Standartları II & $\mathrm{Z}$ & 8 & 4 & 4 \\
\hline Trakya Üniversitesi & Uluslararası Finansal Raporlama Stan.I & $\mathrm{Z}$ & 7 & 3 & 5 \\
\cline { 2 - 6 } & Uluslararası Finansal Raporlama Stan.II & $\mathrm{Z}$ & 8 & 3 & 5 \\
\hline İstanbul Arel Üniversitesi & Muhasebe Standartları I & $\mathrm{Z}$ & 5 & 3 & 7 \\
\cline { 2 - 6 } & Muhasebe Standartları II & $\mathrm{Z}$ & 6 & 3 & 7 \\
\hline
\end{tabular}

IES 4'te etik, mesleki değerler ve davranışlar ayrıntılı bir biçimde açıklanmıştır. Tablo 8 incelendiğinde etik derslerinin tüm UBYO'ların müfredatlarında yer aldığı görülmektedir. Müfredatta çoğunlukla seçmeli ders olarak yer alan bu derslerin de üniversiteler arasında isimleri konusunda bir mutabakatın olmadığ 1 görülmektedir. Daştan (2009) ve Terzi, Şen ve Solak'ın (2013) çalışmalarında etik üzerine verilen derslerin yeterli seviyede olmadığ bulguları dikkate alındığında araştırmamıza konu olan tüm UBYO'ların müfredatlarında etik derslerine yer vermeleri muhasebe eğitimi açısından olumlu bir gelişmedir. 
Tablo 9: Etik Derslerinin Durumu

\begin{tabular}{llcccc}
\hline \multicolumn{1}{c}{ Üniversite } & \multicolumn{1}{c}{ Dersin İsmi } & Z/S & YY & Kredi & AKTS \\
\hline Afyon Kocatepe Üniv. & İş Muhasebe Etiği & $\mathrm{S}$ & 8 & 3 & 5 \\
\hline Burdur MAE Üniv. & Muhasebe Meslek Hukuku ve İş Etiği & $\mathrm{Z}$ & 4 & 2 & 4 \\
\hline Bilecik Şeyh Edebali Üniv. & Meslek Yasası ve Meslek Etiği & $\mathrm{S}$ & 4 & 3 & 4 \\
\hline Dumlupınar Üniv. & Sosyal Sorumluluk ve Etik & $\mathrm{S}$ & 7 & 3 & 4 \\
\hline Isparta Uygulamalı Bil. Üniv. & Muhasebe Meslek Mevzuatı ve Etiği & $\mathrm{S}$ & 5 & 2 & 4 \\
\hline Kayseri Üniv. & Sosyal Sorumluluk ve İş Ahlakı & $\mathrm{Z}$ & 4 & 3 & 4 \\
\hline Uşak Üniv. & Muhasebe Meslek Mevzuatı ve Meslek & $\mathrm{S}$ & 3 & 3 & 3 \\
\hline Trakya Üniv. & Etiği & & & & \\
\hline İstanbul Arel Üniv. (V) & Meslek Etĭ̆i & $\mathrm{S}$ & 4 & 3 & 5 \\
\hline
\end{tabular}

Denetim derslerinin müfredattaki durumları ile ilgili bilgilere Tablo 10 'da yer verilmiştir. IES 8 standardı, diğer 7 standardın denetçilere uyarlanmış hali olarak da açıklanmaktadır (Gökten ve Gökten, 2016: 64). Ayrıca bu standart denetimin uygulanabilir denetim standartlarına ve ilgili yasa ve düzenlemelere uygun olarak yapılıp yapılmadığının da tespit edilmesi gerektiğini vurgular. $\mathrm{Bu}$ anlamda araştırmamıza konu olan üniversitelerin müfredatlarında denetime özgü gerekli bilgilerin ve becerilerin kazandırılmasını sağlayacak denetim derslerinin durumu da araştırılmıştır. Buna göre Türkiye' de lisans düzeyinde muhasebe eğitimi veren tüm üniversitelerinin ders müfredatlarında denetim derslerine yer verdiği görülmektedir.

Tablo 10: Denetim Derslerinin Durumu

\begin{tabular}{llcccc}
\hline \multicolumn{1}{c}{ Üniversite } & \multicolumn{1}{c}{ Dersin İsmi } & Z/S & YY & Kredi & AKTS \\
\hline Afyon Kocatepe Üniv. & Muhasebe ve Vergi Denetimi & Z & 7 & 3 & 5 \\
\hline Burdur MAE Üniv. & Muhasebe Denetimi & Z & 7 & 3 & 4 \\
\hline Bilecik Şeyh Edebali Üniv. & Muhasebe ve Denetim Semineri I-II & $\mathrm{S}$ & $7-8$ & 3 & 3 \\
\cline { 2 - 6 } & Muhasebe ve Denetim Atölyesi I-II & $\mathrm{S}$ & $7-8$ & 3 & 3 \\
\hline Dumlupınar Üniv. & Muhasebe Denetimi & $\mathrm{Z}$ & 7 & 3 & 5 \\
\hline Isparta Uygulamalı Bil. Üniv. & Muhasebe Denetimi & $\mathrm{Z}$ & 7 & 3 & 5 \\
\hline Kayseri Üniv. & Bağımsız Denetim I-II & $\mathrm{Z}$ & $7-8$ & 3 & 5 \\
\hline Uşak Üniv. & Muhasebe Denetimi & $\mathrm{Z}$ & 6 & 3 & 3 \\
\hline Trakya Üniv. & Muhasebe Denetimi & $\mathrm{Z}$ & 7 & 3 & 5 \\
\cline { 2 - 6 } & Muhasebe Denetimi Uygulamaları & $\mathrm{Z}$ & 8 & 3 & 5 \\
\hline İstanbul Arel Üniv. (V) & Muhasebe Denetimi & $\mathrm{Z}$ & 7 & 3 & 6 \\
\hline
\end{tabular}

Uygulama tecrübesi ile ilgili bilgileri içeren IES 5, deneyim kazanmak için yapılacak staj koşullarını açıklamaktadır. Ayrıca Standartta bu tecrübenin mesleki eğitim pragramının tamamlanmasının ardından veya eğitim programıyla eş zamanlı yapılabileceği açıklanmaktadır 
(A8-para 12-13). Araştırmamıza konu olan üniversitelerdeki staj ya da işbaşında eğitim durumları Tablo 9'da yer almaktadır. Buna göre Türkiye'de lisans düzeyinde muhasebe eğitimi veren tüm devlet üniversitelerinin ders müfredatları incelendiğinde öğrencilerin öğrenim süreleri boyunca staj veya işbaşında eğitim aldıkları görülmektedir. Araştırmamızdaki tek vakıf üniversitesi olan Arel Üniversitesi’nin müfredatında staj üzerine bir derse rastlanmamıştır.

Tablo 11: Staj veya İşbaşında Eğitim Durumu

\begin{tabular}{lllcc}
\hline \multicolumn{1}{c}{ Üniversite } & \multicolumn{1}{c}{ Dersin İsmi } & YY & Kredi & AKTS \\
\hline Afyon Kocatepe Üniversitesi & Işbaşında Eğitim & 7 & 6 & 30 \\
\hline Burdur MAE Üniversitesi & Işbaşında Eğitim & 8 & 8 & 30 \\
\hline Bilecik Şeyh Edebali Üniversitesi & Staj (20 işgünü) & 4 & 2 & 2 \\
\hline Dumlupınar Üniversitesi & I. Staj (20 işgünü) & 5 & 0 & 4 \\
\cline { 2 - 5 } & II.Staj (20 işgünü) & 7 & 0 & 4 \\
\hline Isparta Uygulamalı Bil. Üniversitesi & Staj (30 işünü) & 8 & 0 & 8 \\
\hline Kayseri Üniversitesi* & Muhasebe ve Fin Uyg. I & 7 & 3 & 10 \\
\cline { 2 - 5 } & Muhasebe ve Fin Uyg. II & 8 & 3 & 10 \\
\hline Uşak Üniversitesi & Yaz Stajı (40 işgünü) & 6 & 8 & 8 \\
\hline Trakya Üniversitesi & Meslek Stajı (40 işgünü) & 6 & - & - \\
\hline İstanbul Arel Üniversitesi (V) & & - & - & - \\
\hline
\end{tabular}

* Kayseri Üniversitesi’nin ilgili dersinin ders içerikleri incelendiğinde staj uygulaması yapıldığı belirlenmiştir.

\section{SONUÇ}

Türkiye'de lisans düzeyinde özellikli alanlara öğrenci yetiştiren Uygulamalı Bilimler Yüksekokulları ve Uygulamalı Bilimler Fakülteleri, 4 yıllık muhasebe eğitimini ders çeşitliliği ve ders kredisi bakımından kapsamlı bir şekilde vermektedir. Verilen bu eğitimle sektörün ihtiyaç duyduğu kalifiye işgücünü yetiştirmeyi amaçlamaktadırlar. Bu yüksekokulları kurulana kadar Türkiye'de lisans düzeyinde muhasebe eğitimi sadece İktisadi ve İdari Bilimler Fakülteleri ve İşletme Fakülteleri tarafından verilmekte idi. Bu fakültelerin öğrencileri ağırlıklı olarak öğrenimleri boyunca Genel Muhasebe, Dönemsonu Muhasebe İşlemleri, Maliyet Muhasebesi gibi temel muhasebe derslerini zorunlu ders olarak, Şirketler Muhasebesi ve bazı ihtisas muhasebesi derslerini seçmeli ders olarak görmektedirler. Uygulamalı Bilimler Yüksekokulları müfredatlarında, bu fakültelerde verilen temel derslerin yanında muhasebe standartları, meslek etiği, muhasebe paket programları, banka muhasebesi, konaklama işletmeleri muhasebesi, inşaat muhasebesi, dış ticaret işlemleri muhasebesi, sigorta muhasebesi gibi özellikli derslerin yanısıra, ileri muhasebe bilgileri içeren derslere de yer vermektedir.

Kaliteli muhasebe eğitiminin temel anahtarlarından birisi bu eğitimi veren yükseköğretim kurumlarının sahip oldukları kaliteli ders müfredatlarıdır. Bu çalışmada, lisans düzeyinde eğitim veren Uygulamalı Bilimler Yüksekokulu (UBYO), Uygulamalı Bilimler Fakültesi (UBF) ve diğer uygulamalı eğitim veren yüksekokullarının muhasebe bölümlerinde verilen eğitimin Uluslararası Eğitim Standartlarını ne ölçüde karşıladığı belirlenmeye çalışılmıştır. Çalışma sonucunda; 
- UBYO'dan mezun olacak bir öğrencinin 4 y1llık muhasebe eğitimi boyunca ortalama 161 kredilik ders alması gerektiği,

- UBYO'lardaki muhasebe bölümlerinde sunulan seçmeli derslerin kredi oranları bakımından yeterli seviyelerde olduğu,

- Müfredattaki tüm ders sayıları bakımından araştırmamıza konu olan üniversitelerin öğrencilerine zorunlu derslerde \%32, seçmeli derslerde \%27 oranında öğrencilerine muhasebe ve denetim dersi verdiği,

- Araştırmamıza konu olan üniversitelerin IES 2'ye uygun ders müfredatlarına sahip oldukları,

- Ders sayıları bakımından bu okullarda öğrenim gören öğrencilerin, yök dersleri içinde iki adet yabancı dil dersi hariç olmak üzere, öğrenimleri boyunca yabancı dil eğitimini $\% 5$ oranında zorunlu olarak aldıkları,

- Muhasebe standartları dersinin bir üniversite hariç tüm üniversitelerde zorunlu ders olarak müfredatta yer aldığı,

- Etik ile ilgili derslerin de tüm UBYO'ların müfredatlarında yer aldığı,

- Türkiye'de lisans düzeyinde muhasebe eğitimi veren tüm üniversitelerinin ders müfredatlarında denetim derslerine yer verdiği,

- Türkiye'de lisans düzeyinde muhasebe eğitimi veren tüm devlet üniversitelerin öğrencilerinin öğrenim süreleri boyunca staj veya işbaşında eğitim aldıkları, ortaya çıkmıştır.

Çalı̧̧mamızda Türkiye'de lisans düzeyinde eğitim veren eğitim kurumlarının müfredatları incelenerek, meslek mensubu yetiştiren bu kurumların, söz konusu standartlara ne kadar uygun müfredatlara sahip oldukları da belirlenmeye çalışılmıştır. Bu standartların tamamı meslek mensubu yetiştiren araştırmamıza konu olan eğitim kurumları açısından değerlendirildiğinde, bu kurumların Uluslararası Eğitim Standartlarına uygun müfredata sahip olduklarını söylenebilmektedir. Yapılan araştırma neticesinde ders müfredatlarının IES 2'de tanımlanmış yeterlilik alanlarına uygun olduğu, birbirine içiçe geçmiş iki standart olan IES 3 ve IES 5'te (Gökten, Gökten, 2016: 62) açıklanan staj konusunda araştırmamızdaki tüm devlet üniversitelerinin gerek işbaşı eğitim gerekse yaz stajlarıyla uyum gösterdiği, IES 4'te dikkat çekilen etik konusunda tüm üniversitelerin müfredatlarında bu derse yer verdiği, denetime özgü gerekli becerilerin kazandırılmasına dikkat çeken IES 8 standardına uyumlu olarak araştırmamıza konu olan her üniversitenin denetime dersine müfredatlarında yer verdiği sonucuna ulaşılmıştır. Ayrıca IES 6, meslek mensuplarının mesleki yeterliliğini değerlendirilmesine yöneliktir. $\mathrm{Bu}$ anlamda araştırmamıza konu olan üniversitelerde ders müfredatlarında yer almamasına rağmen bölüm öğretim üyeleri tarafindan yapılan staj sonu değerlendirme mülakatlarının bu standarda uyumlu olduğu söylenebilmektedir.

Yapılan araştırmanın sonucunda Türkiye'de birçok üniversitenin ders müfredatları incelendiğinde aynı nitelikteki muhasebe derslerinin isimleri, ders kredileri ve AKTS'leri konusunda üniversiteler arasında bir mutabakatın olmadığı görülmektedir. Bu farklılıkların ortadan kaldırılması için bu derslerin isimleri, ders kredileri ve AKTS'leri ile ilgili bir standardizasyon işlemi yapılması gerekmektedir. Oluşturulacak standart sistem yatay geçiş, dikey geçiş, yaz okulu ve ilgili ders muafiyetlerinde sorunlar yaşanmasını engelleyecektir. 


\section{KAYNAKÇA}

Can, A. V. ve Demirci, Ş. D. (2016). "Uluslararası muhasebe eğitim standardı 2 muhasebe eğitim programlarının içeriğine uyum: Sakarya üniversitesi örneği” Uluslararası yönetim ve iktisat ve işletme dergisi, ICAFR 16 Özel sayısı, 319-338.

Demirci, Ş.D., Kıymaz, M., \& Ağsakal, A. (2015). "Yükseköğretimde verilen muhasebe eğitiminin muhasebe mesleğine giriş sınavlarına katkısı: Devlet üniversiteleri işletme ve muhasebe bölümleri üzerine bir araştırma" Gümüşhane üniversitesi sosyal bilimler elektronik dergisi, Cilt: 6, Sayı: 13, 264-280.

Erol, M. ve Atmaca, M. (2015). "Türkiye'de lisans düzeyinde muhasebe eğitiminin gelişimi", Muhasebe ve finans tarihi araştırmaları dergisi, 172-191.

Gökten Okan, P. ve Gökten, S. (2016). "Uluslararası eğitim standartlarına genel bakış: Geçerliliğinin türkiye açısından değerlendirilmesi” Gazi üniversitesi sosyal bilimler dergisi, Cilt: 3, Sayı: 6, 49-66.

International Education Standart 2: Content of professional accounting education programs (2005). International federation of accountants. www.ifac.org . Erişim tarihi: 10.02.2018.

Öztürk, M. S., Erdoğan, M. (2017). "Batı akdeniz bölgesinde yer alan üniversitelerdeki muhasebe eğitimine yönelik bir araştırma” Mehmet akif ersoy üniversitesi sosyal bilimler enstitüsü dergisi, Cilt: 9, Sayı: 21, 162-174.

Şengel, S. (2010). "Sürekli muhasebe meslek eğitiminin önemi ve bir değerlendirme”, Muhasebe ve finansman dergisi, Sayı:47, 2010, 81-94.

Tazegül, A. ve Karabayır, M. E. (2015). "Muhasebe eğitim standartlarının lisans eğitiminde gerçekleşme durumu: Öğrenci kazanımları değerlendirme çalışması”, 34. Türkiye muhasebe eğitimi sempozyumu, 13-17 Mayıs 2015, Antalya.

Terzi, S., Șen Kıymetli, İ. \& Solak, B. (2013). "Bologna sürecinin muhasebe eğitimine etkisi: Üniversitelerin ișletme bölümlerinin ders programları üzerine bir inceleme" Muhasebe ve finansman dergisi, 59, Temmuz 2013, 83-99.

Uyar, S. (2008). Uluslararası eğitim standartları (IES) ve akdeniz üniversitesi’nde muhasebe eğitimi. MÖDAV. 2008/1. 79-107.

Ünal, O. ve Doğanay, M. (2009). "Lisans düzeyindeki muhasebe eğitimimnin etkinliği: Sayıştay özelinde ampirik bir çalışma" Sayıştay dergisi, Sayı: 74-75, Temmuz-Aralık, 117-138.

Zaif, F. ve Ayanoğlu, Y. (2007). "Muhasebe eğitiminde kalitenin arttırılmasında ders programlarının önemi: Türkiye'de bir inceleme" Gazi üniversitesi iktisadi ve idari bilimler fakültesi dergisi, Cilt: 9, Sayı: 1, 115-136.

https://www.iaesb.org/about-iaesb Erişim tarihi: 10.02.2018. 


\section{Extended Summary}

\section{The Impact of Schools of Applied Sciences on Accounting Education: An Analysis on Curricula of Accounting Departments}

Accounting education at the level of bachelor degree is given in the Faculties of Economics and Administrative Sciences or predominately in the Management Departments of Management Faculties in Turkey. However, the education in those departments is far away from practice and it is carried out theoretically. The adverse events in the field of accounting and audit which have been seen recently worldwide have increased the importance of accounting education. It has come out that accounting needs well-educated and well-equipped workforce that knows the sector very well rather than the employees who keep records.

Considering that Schools of Applied Sciences give education at the level of bachelor degree and were established in order to train students who have deep training at specific fields, who take practical education in cooperation with the sector via compulsory summer training or job shadowing programmes during their education and who have foreign language proficiency, it has been attempted to determine to what extend the education in the accounting departments of SAS can fulfill the International Education Standards in the present study. At the end of the study, following results were obtained:

- A student who is supposed to graduate from SAS must take courses of 161 credits averagely during his four year accounting education.

- The elective courses given in the accounting departments of SAS are at the adequate level in terms of credit rate.

- In terms of all course hours in the curricula, the universities involved in our study give accounting and audit courses to their students at the level of $32 \%$ for compulsory classes and at the rate of $27 \%$ for elective courses.

- The curricula of the universities involved in our study are in accordance with IES 2.

- In terms of course hours, the students in those schools take foreign language education compulsorily in the rate of $5 \%$, excluding two foreign language classes in the Council of Higher Education.

- The course of accounting standards are in the curricula as a compulsory course, except for only one university.

- The courses related to Ethics are in the curricula of all SAS.

- All universities which give accounting education at the level of bachelor degree in Turkey give place to audit courses in the curricula.

- The students of the state universities which give accounting education at the level of bachelor degree in Turkey involve in practical training or job shadowing programmes during their educations.

In our study, by analyzing the curricula of the educational institutions which give education at the level of bachelor degree in Turkey, it was also tried to determine how appropriate curricula those institutions, training member of a profession, have according to the relevant standards. Considering all of those standards in terms of the educational institutions involved in our study, it could be inferred that those institutions' curricula are in accordance with International Education Standards. In consequence of the research, it was concluded that the curricula are appropriate to the efficiency fields defined in IES 2; not only job shadowing 
programmes but also summer practical trainings of the whole state universities involved in our study are matching to the practical training described in IES 3 and IES 5, which are two interpenetrating standards (Gökten, Gökten, 2016: 62); all of those universities give place to the Ethics, which is highlighted in IES 4, in their curricula; each of the universities involved in our study give place to the audit courses in their curricula in accordance with IES standards which emphasize the acquisition of the skills specific to audit. Moreover, IES 6 is aimed at evaluating the professional efficancy of the members of the profession. In this sense, it could be stated that the evaluation interviews which are made by the lecturers at the end of the practical training are consistent with this standard although the curricula of the universities involved in our study do not include this standard.

As a final conclusion, it is seen that there is no agreement among the universities in terms of course names, credits and ECTS considering accounting courses which are at the same quality when the curricula of many universities were analyzed. A standardization must be made in terms of names, credits and ECTS of those courses in order to remove those differences. With this standardization, possible problems which might be seen in lateral transfer, vertical transfer, summer school and relevant course exemption could be prevented. 